\title{
Characterisation of autoantibodies to neutrophil granule constituents among patients with reactive arthritis, rheumatoid arthritis, and ulcerative colitis
}

Henning Locht, Thomas Skogh, Allan Wiik

\begin{abstract}
Objective-To study the frequency and distribution of antineutrophil cytoplasmic autoantibodies (ANCA) among patients with reactive arthritis $(\operatorname{Re} A)$, rheumatoid arthritis (RA), and ulcerative colitis (UC) using different immunological methods.

Methods-Fifty serum samples from patients with reactive arthritis (26 with acute disease and 24 with chronic disease-that is disease of more than one year) were analysed for ANCA with indirect immunofluorescence, enzyme linked immunosorbent assay (ELISA) with six different neutrophil granule proteins as antigens, and immunoblotting on whole neutrophil extract and extracts of azurophil and specific granules. Thirty serum samples from patients with RA and UC served as controls in ELISA and indirect immunofluorescence.
\end{abstract}

Results-Sixteen per cent of patients with ReA were positive in immunofluorescence compared with $30 \%$ of patients with RA, and $70 \%$ of patients with UC. Thirty two per cent of patients with $\operatorname{ReA}$ were positive in ELISA. Antibodies directed against lactoferrin occurred in $20 \%$, antibodies against bactericidal permeability increasing protein (BPI), elastase, cathepsin G, myeloperoxidase, and proteinase 3 were found in $8 \%, 2 \%, 2 \%, 8 \%$, and $6 \%$, respectively. Overall, $50 \%$ of RA sera and $53 \%$ of UC sera were positive in one or more ELISA assays, the corresponding figures for antibodies against individual antigens were for RA $7 \%, 3 \%, 0 \%, 13 \%, 47 \%, 17 \%$ and for UC $13 \%, 20 \%, 0 \%, 23 \%, 10 \%$, and $17 \%$. In immunoblotting, bands corresponding to lactoferrin and BPI were recognised in $44 \%$ and $22 \%$ of ReA sera.

Conclusion-Antibodies against neutrophil granule antigens are often found in patients with $\operatorname{ReA}$, primarily among those with chronic disease. The different methods detect various subsets of antibodies, with immunoblotting being the most and immunofluorescence the least sensitive. (Ann Rheum Dis 2000;59:898-903) Dr Henning Locht, Department of

Autoimmunology, Building 81, Room 524, Statens

Serum Institute, DK-2300

Copenhagen S, Denmark

Email: hlo@ssi.dk

Accepted for publication 10 April 2000
Antineutrophil cytoplasmic antibodies (ANCA) are diagnostic hallmarks of various forms of small vessel vasculitides. ${ }^{1-3}$ ANCA directed against proteinase 3 (PR3) are a reliable seromarker for Wegener's granuloma- tosis and produce a coarse granular cytoplasmic staining pattern (C-ANCA) on ethanol fixed polymorphonuclear leucocytes. ${ }^{3}$ The artefactual perinuclear (P-ANCA) staining pattern seen when antibodies are directed against myeloperoxidase (MPO) occurs in other small vessel disease, such as microscopic polyangiitis or the Churg-Strauss syndrome. ${ }^{12}$ Other neutrophil granule proteins may also be targeted by ANCA and give rise to a P-ANCA pattern - for example, lactoferrin (Lf), human leucocyte elastase (HLE), or cathepsin G (Cat G). ${ }^{4}$ These types of P-ANCA may occur in non-vasculitic conditions like rheumatoid arthritis (RA), systemic lupus erythematosus, and inflammatory bowel disease (IBD)..$^{5-9}$ Antibodies against bactericidal permeability increasing protein (BPI) have been found in IBD, especially ulcerative colitis (UC), and to a lesser extent in Crohn's disease. ${ }^{10}{ }^{11} \mathrm{~A}$ number of clinical features are shared between IBD and the seronegative spondyloarthropathies, and ANCA, predominantly directed against Lf, have also been shown in sera from patients with reactive arthritis $(\operatorname{ReA})$ as well as in $\mathrm{UC} .{ }^{12}$

This study aimed at investigating the prevalence, possible clinical relevance, and antigen specificity of ANCA in ReA, using three different methods: indirect immunofluorescence (IIF), enzyme linked immunosorbent assay (ELISA), and immunoblotting (IB). Thirty serum samples from patients with UC and RA served as disease controls.

\section{Patients and methods}

PATIENTS

Serum samples from 50 consecutive outpatients with ReA were included. They comprised 37 men (mean age 34 years, range 18-52) and 13 women (mean age 40 years, range 22-56). The diagnosis of ReA was based on the following criteria: a mono- or oligoarthritis, predominantly of the legs, after an enteric or urogenital infection. The triggering microorganisms were identified by culture or serology, routinely performed at the Department of Clinical Microbiology. In cases where no preceding infection could be disclosed the diagnosis of $\operatorname{ReA}$ was based on a combination of arthritis and one or more of the following manifestations: acute anterior uveitis/ conjunctivitis, urethritis, sacroiliac joint arthritis, circinate balanitis, keratoderma blenorrhagia, or dactylitis. Patients with ReA were divided into acute or chronic (that is, disease of more than one year). 
Sixty randomly selected deep frozen serum samples (from the Serumbank, Department of Autoimmunology, Statens Serum Institute, Copenhagen, Denmark) were used as disease controls. Thirty samples were from patients with UC and 30 from patients with RA.

\section{ANTIBODIES}

Mouse monoclonal antibodies with the following specificities were used: human Lf (2.88 $\mathrm{mg} / \mathrm{ml}$ ) and PR3 $(1.4 \mathrm{mg} / \mathrm{ml}$ ) (Department of Immunology, Statens Serum Institute, Copenhagen, Denmark), BPI, and HLE (1 mg/ml) (Pharmingen, San Diego, CA, USA). We also used rabbit polyclonal antibodies directed against MPO or Cat G (DAKO, Glostrup, Denmark). As secondary antibodies the following were used: alkaline phosphatase conjugated goat antihuman IgG ( $\gamma$ chain specific) (Sigma, St Louis, MO, USA), goat antimouse IgG (Sigma) and goat antirabbit IgG (Sigma), peroxidase conjugated $\mathrm{F}\left(\mathrm{ab}^{\prime}\right)_{2}$ rabbit antihuman IgG ( $\gamma$ chain specific) (DAKO).

IIF MICROSCOPY

Freshly isolated human leucocytes were ethanol fixed on microscope slides and used for ANCA detection by IIF microscopy as described in detail elsewhere. ${ }^{4}$ Initial dilution of sera was $1: 20$ in phosphate buffered saline $(\mathrm{pH}$ 7.2). Sera were scored as P-ANCA/C-ANCA or negative.

ENZYME LINKED IMMUNOSORBENT ASSAYS (ELISA) PR3-ANCA ELISA

Microtitre plates (Maxisorp, Nunc, Roskilde, Denmark) were coated overnight at $4^{\circ} \mathrm{C}$ with $100 \mu \mathrm{l} /$ well human PR3 $(1 \mu \mathrm{g} / \mathrm{ml}$, in $0.015 \mathrm{M}$ $\mathrm{Na}_{2} \mathrm{CO}_{3}, 0.035 \mathrm{M} \mathrm{NaHCO}, 0.02 \% \quad(\mathrm{w} / \mathrm{v})$ $\mathrm{NaN}_{3}, \mathrm{pH}$ 9.6) purified from azurophilic granules as described. ${ }^{13}$ The purified PR3 was tested in our laboratory and did not react with antibodies against HLE, Cat G, MPO, or Lf. ${ }^{14}$ After washing, patient or control sera diluted $1: 100$ in incubation buffer $(0.04 \mathrm{M}$ Tris- $\mathrm{HCl}$, $0.01 \mathrm{M}$ Tris-base, $0.15 \mathrm{M} \mathrm{NaCl}, 0.05 \%$ Tween $20(\mathrm{v} / \mathrm{v}), 0.02 \% \quad \mathrm{NaN}_{3}(\mathrm{w} / \mathrm{v}), 0.2 \%$ bovine serum albumin (w/v), $\mathrm{pH} 7.5)$ were incubated for one hour. Plates were then washed and incubated for one hour at ambient temperature with alkaline phosphatase conjugated goat antihuman IgG antibodies (Sigma) diluted $1: 4000$ in incubation buffer. $p$-Nitrophenylphosphate was used as substrate. The positive cut off value $(10 \mathrm{U} / \mathrm{ml})$ was calculated from a standard curve and defined as the mean value of 100 normal control sera +3 SD.

$M P O-A N C A$ ELISA and Lf-ANCA ELISA MPO-ANCA ELISA and Lf-ANCA ELISA were performed essentially as described for the PR3-ANCA ELISA except that the microtitre plates were coated with purified MPO (2 $\mu \mathrm{g} / \mathrm{ml}$; kindly provided by Professor I Olsson, Lund, Sweden). The MPO preparation used has previously been tested by us and others and found free of contamination with Lf. ${ }^{15}$ Human milk Lf was used in a concentration of $10 \mu \mathrm{g} / \mathrm{ml}$ (Sigma). The positive cut off value for the
MPO-ANCA ELISA was $10 \mathrm{U} / \mathrm{ml}$ and for the Lf-ANCA ELISA $5 \mathrm{U} / \mathrm{ml}$.

ELISA kits for the detection of HLE-ANCA and Cat G-ANCA were purchased from Shield Diagnostics Ltd (Dundee, UK) and tests were carried out according to the protocol provided with the kit. Positive cut off value was determined as the mean $+3 \mathrm{SD}$ of 20 normal sera.

An ELISA kit for the demonstration of BPIANCA was obtained from DLD Diagnostica $\mathrm{GmbH}$ (Hamburg, Germany) and used according to the manufacturer's instructions. The positive cut off value was $4 \mathrm{U} / \mathrm{ml}$.

INHIBITION ELISA

A solid phase inhibition experiment was performed on sera positive for antibodies against PR3, MPO, or Lf. Five randomly chosen serum samples from each specificity were diluted 1:100 in incubation buffer and incubated for 30 minutes at $37^{\circ} \mathrm{C}$ on a precoated (PR3, MPO, or Lf respectively) ELISA plate. After 30 minutes sera were aspirated and passed over to the adjacent coated well. This procedure was repeated eight times. Inhibition was considered positive if the difference in $\mathrm{U} / \mathrm{ml}$ between inhibited or uninhibited serum was $>20 \%$.

ISOLATION OF NEUTROPHIL GRANULOCYTES AND PREPARATION OF ANTIGEN EXTRACTS

Human neutrophil granulocytes were isolated from buffy coats as described elsewhere. ${ }^{14}$ The neutrophil suspension $\left(3 \times 10^{8}\right.$ cells $\left./ \mathrm{ml}\right)$ was sonicated four times for 20 seconds each in 1 $\mathrm{M} \mathrm{NaCl}$ containing $0.5 \mathrm{mM}$ phenylmethylsulphonyl fluoride (Sigma). Insoluble constituents were removed by centrifugation.

Neutrophils were lysed by nitrogen cavitation and subfractionated on Percoll density gradients to yield three distinct bands of azurophilic granules, specific granules, and a membrane fraction. ${ }^{16}$ Percoll was removed by ultracentrifugation at $100000 \mathrm{~g}$ for three hours. The azurophilic and specific granules were extracted by sonication as described for whole cells. These extracts were used in order to identify the reactivities on blots of whole neutrophil extract.

Human lymphocytes $\left(3 \times 10^{8}\right.$ cells $\left./ \mathrm{ml}\right)$ were isolated from buffy coats by centrifugation through Lymphoprep (Nycomed Pharma, Oslo, Norway) at $400 \mathrm{~g}$ for 15 minutes. The lymphocyte-rich interphase was harvested and resuspended in RPMI containing $10 \%$ fetal calf serum. After incubation in a plastic flask (Nunc) for one hour at $37^{\circ} \mathrm{C}$ in a $\mathrm{CO}_{2}$ incubator to let monocytes adhere, the lymphocytes were pelleted, extracted by sonication in $1 \mathrm{M}$ $\mathrm{NaCl}$, and centrifuged as described for whole neutrophil extract.

\section{IMMUNOBLOTTING}

Extracts of neutrophil granulocytes $(3.0 \mathrm{mg} /$ $\mathrm{ml}$ ), azurophilic and specific granules (700 $\mu \mathrm{g} / \mathrm{ml}$ ) were suspended in non-reducing sample buffer and boiled for five minutes. Separation was carried out by sodium dodecyl sulphatepolyacrylamide gel electrophoresis using $12 \%$ 
polyacrylamide gels (Novex, San Diego, USA). The separated antigens were blotted onto 0.2 $\mathrm{mm}$ nitrocellulose membranes in a semidry blotting system. Blots were blocked for two hours in immunoblot incubation buffer $(0.01$ $\mathrm{M}$ Tris- $\mathrm{HCl}, 0.15 \mathrm{M} \mathrm{NaCl}, \mathrm{pH}$ 7.4) containing $3 \%$ horse serum $(\mathrm{v} / \mathrm{v})$. They were then washed three times for five minutes and incubated for two hours with sera or specific antibodies diluted in incubation buffer containing $1 \%$ horse serum $(\mathrm{v} / \mathrm{v})$ and $0.1 \%$ Tween $20(\mathrm{v} / \mathrm{v})$. The sera were diluted $1 / 100$ and secondary $\gamma$ chain specific peroxidase conjugated $\mathrm{F}\left(\mathrm{ab}^{\prime}\right)_{2}$ rabbit antihuman IgG antibodies were diluted 1/3000 (DAKO). After washing, blots were developed with the ECL western blotting detection system (Amersham, Aylesbury, UK). Monoclonal and polyclonal antibodies directed against PR3, MPO, Lf, HLE, BPI, Cat G, or a pool from seven healthy blood donors were used as controls.

To ascertain myeloid cell specificity, extract from human lymphocytes handled according to the same procedures was used.

OTHER LABORATORY ANALYSES

IgM rheumatoid factor and HLA-B27 were also analysed. Blood samples to record haemoglobin and $\mathrm{C}$ reactive protein (CRP) were drawn at the same time as those for the ANCA tests.

\section{STATISTICS}

The $\chi^{2}$ test and Fisher's exact test, two sided, were used to compare the frequency of ANCA in the various disease groups.

\section{Results}

Twenty six patients had acute disease (mean six months, range 1-12) and 24 had chronic disease (mean 7.4 years, range 1.2-19). The triggering infection was Yersinia enterocolitica in 10, Salmonella species in four, Campylobacter jejuni in seven, and Chlamydia trachomatis in nine patients. In 20 cases culture or serology could disclose no triggering infection. However, six of these patients reported symptoms of enterocolitis preceding the arthritis.

Forty per cent had extra-articular manifestations, predominantly acute anterior uveitis/ conjunctivitis (12 patients), urethritis (10), circinate balanitis (three), erythema nodosum (three), and keratoderma blenorrhagia (one). The percentages of patients with affected joints at the time of ANCA testing were: knee (65\%), ankle (61\%), sacroiliac joint (42\%), hip (24\%), metatarsophalangeal/dactylitis (20\%), wrist (8\%), elbow (8\%), metacarpophalangeal/ proximal interphalangeal $(4 \%)$.
Overall, 88\% carried the HLA-B27 antigen. Numbers of patients found positive for IgM rheumatoid factor were for the patients with $\mathrm{ReA} / \mathrm{UC} / \mathrm{RA}$ respectively one, two, and 28 .

INDIRECT IMMUNOFLUORESCENCE (IIF)

Serum samples from the 50 patients with ReA, 30 with UC, and 30 with RA were screened for the presence of IgG antineutrophil cytoplasmic autoantibodies by IIF microscopy on ethanol fixed leucocytes. Among the patients with ReA eight sera $(16 \%)$, all of which were from patients with chronic disease, gave a P-ANCA pattern. None of the samples from the 26 patients with acute $\operatorname{ReA}$ gave positive results in IIF $(p<0.005)$. The corresponding figures for the patients with UC were 21 positive $(70 \%)$, of whom 20 had P-ANCA and one had a C-ANCA pattern. Nine patients with RA $(30 \%)$ were P-ANCA positive.

SPECIFICITIES OF ANCA DETECTED BY ELISA

All serum samples were analysed by ELISA for their ability to detect six different neutrophil cytoplasmic antigens-that is, PR3, MPO, BPI, Lf, Cat G, and HLE. Sixteen ReA sera $(32 \%)$ were positive in ELISA. Antibodies against Lf were found in 10, MPO-ANCA in four, BPI-ANCA in four, PR3-ANCA in three, Cat G-ANCA and HLE-ANCA in one serum each (table 1). Five of the 16 serum samples reacted with more than one antigen. Eleven sera were from the group of 24 patients with chronic or chronic intermittent ReA disease $(46 \%)$ and five $(19 \%)$ from the remaining 26 with acute ReA disease. This difference between patients with chronic $v$ acute disease reached significance $(p<0.05)$. Of the 16 sera, four gave rise to a P-ANCA pattern in IIF. Four sera were positive in IIF (all P-ANCA), but failed to react with any of the six ELISA antigens.

In the group of patients with UC 16 (53\%) were positive in ELISA. Antibodies against Lf were seen in four, MPO-ANCA in three, BPIANCA in six, PR3-ANCA in five, Cat G-ANCA in seven; no patient had HLEANCA. Eight patients had antibodies to more than one antigen. Of the 16 ELISA positive sera, 11 were also positive in IIF (10 P-ANCA and 1 C-ANCA). The remaining ten sera which gave a P-ANCA pattern in IIF did not, however, react with any of the six antigens in ELISA.

Among the control patients with RA 15 were positive in ELISA ( $50 \%$ ). Two had Lf-ANCA, 14 MPO-ANCA, one BPI-ANCA, five PR3ANCA, four Cat G-ANCA, and none had HLE-ANCA. Eight patients had antibodies to

Table 1 Results of IgG ELISA determinations with six neutrophil granule constituents as antigens, IgM rheumatoid factor, and IgG indirect immunofluorescence (IIF) antineutrophil cytoplasmic antibodies (ANCA) among 50 patients with reactive arthritis (ReA), 30 control patients with ulcerative colitis (UC) and 30 controls with rheumatoid arthritis (RA). Results are shown as numbers (\%)

\begin{tabular}{|c|c|c|c|c|c|c|c|c|}
\hline & Anti-PR3* & Anti-MPO* & Anti-Lf $f^{\star}$ & Anti-HLE* & Anti-Cat $G^{\star}$ & Anti-BPI* & $\operatorname{Ig} M R F^{\star}$ & $A N C A(I I F)$ \\
\hline Acute $\operatorname{ReA}(\mathrm{n}=26)$ & $2(4)$ & & $2(4)$ & $1(2)$ & & & $1(2)$ & \\
\hline Chronic ReA $(n=24)$ & $1(2)$ & $4(8)$ & $8(16)$ & & $1(2)$ & $4(8)$ & & $8 P^{\star}(16)$ \\
\hline $\mathrm{UC}(\mathrm{n}=30)$ & $5(17)$ & $3(10)$ & $4(13)$ & & $7(23)$ & $6(20)$ & $2(7)$ & $20 \mathrm{P}, 1 \mathrm{C}^{\star}(70)$ \\
\hline $\mathrm{RA}(\mathrm{n}=30)$ & $5(17)$ & $14(47)$ & $2(7)$ & & $4(13)$ & $1(3)$ & $28(93)$ & $9 \mathrm{P}(30)$ \\
\hline
\end{tabular}

${ }^{\star} \mathrm{PR} 3=$ proteinase $3 ; \mathrm{MPO}=$ myeloperoxidase $\mathrm{Lf}=$ lactoferrin HLE $=$ human leucocyte elastase Cat $\mathrm{G}=$ cathepsin $\mathrm{G} ; \mathrm{BPI}=$ bactericidal permeability increasing protein; $\mathrm{RF}=$ rheumatoid factor; $\mathrm{P}=\mathrm{P}-\mathrm{ANCA} ; \mathrm{C}=\mathrm{C}-\mathrm{ANCA}$. 
more than one antigen. The number of MPOANCA positive sera was unexpectedly high, but the individual unit values were low or borderline with a mean (SD) of 16 (5) $\mathrm{U} / \mathrm{ml}$, which is less than the double cut off level of the assay. Of the 15 ELISA positive sera, four gave a P-ANCA pattern in IIF. Five sera were positive in IIF (all P-ANCA), but failed to react with any of the six ELISA antigens.

INHIBITION ELISA

Fifteen serum samples, five each positive for PR3-ANCA, MPO-ANCA, and Lf-ANCA respectively were absorbed by passing the samples over precoated ELISA plates. All but one, a borderline PR3-ANCA positive serum, showed at least $20 \%$ reduction in $\mathrm{U} / \mathrm{ml}$ compared with unabsorbed sera.

IMMUNOBLOTTING

Monoclonal or polyclonal antibodies against PR3, MPO, HLE, BPI, Cat G, and Lf all showed reactivity in immunoblotting to proteins of the expected molecular weight when tested on sonicated extracts of whole neutrophils, azurophilic and specific granules.

A double band of $78 \mathrm{kDa}$ corresponding to Lf was recognised by $22 \mathrm{ReA}$ sera, and seen equally in neutrophil and specific granule extract. Eight of these sera were also positive in the Lf-ANCA ELISA. A band corresponding to the $55 \mathrm{kDa}$ antigen, stained with the anti-BPI monoclonal antibody, was recognised by $11 \mathrm{ReA}$ sera on blots of neutrophil granule extract. Four of the 11 sera reacting with the 55 $\mathrm{kDa}$ band were positive in the BPI-ANCA ELISA. In the azurophilic granule extract a smear in the $28-34 \mathrm{kDa}$ region was weakly stained by a few sera all of which, however, were negative in the ELISA (fig $1 \mathrm{~A}$ and $\mathrm{B}$ ). Furthermore, unknown antigens of $60 \mathrm{kDa}$ and $16 \mathrm{kDa}$ were recognised by seven and four sera respectively in both neutrophil and specific granule extracts. To study the neutrophil specificity of these proteins recognised by ReA sera, they were also tested for reactivity with sonicated and $\mathrm{NaCl}$ extracted lymphocytes in immunoblotting. There was, however, no reactivity to antigens of the abovementioned molecular weights.

When the results obtained by ELISA, immunoblotting, and IIF were compared with clinical status and other laboratory data, there was no correlation with triggering infections, numbers of affected joints or extra-articular manifestations, neither was there any correlation between the presence of ANCA and CRP, haemoglobin, or HLA-B27 status, respectively. Patients with longstanding (chronic) ReA disease, however, had a higher prevalence of ANCA than patients with a short disease course. This difference was significant for ANCA as detected by IIF and ELISA. The same trend was observed for Lf-ANCA and BPI-ANCA in immunoblotting, though it did not reach significance $(\mathrm{p}<0.25$ and $<0.1$ respectively). A comparison of the group of patients with chronic ReA with the group with RA showed that Lf-ANCA was significantly more prevalent in $\operatorname{ReA}(\mathrm{p}<0.02)$. Cat
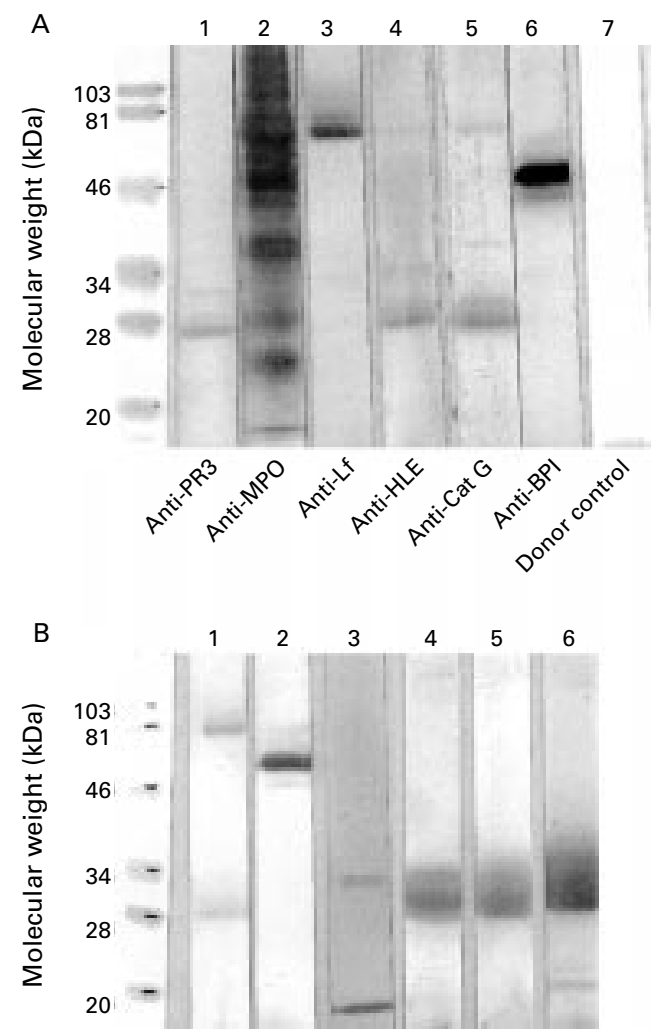

Figure 1 (A) Immunoblot of whole granulocyte extracts, separated by sodium dodecyl sulphate-polyacrylamide gel electrophoresis (SDS-PAGE), incubated with human anti-proteinase 3 (anti-PR3) positive vasculitis serum (lane 1), rabbit anti-myeloperoxidase (anti-MPO) serum (lane 2), mouse monoclonal anti-lactoferrin (anti-Lf; lane 3), mouse monoclonal anti-human leucocyte elastase (anti-HLE; lane 4), rabbit polyclonal anti-cathepsin $G$ (anti-Cat G; lane 5), mouse monoclonal anti-bactericidal permeability increasing protein (anti-BPI; lane 6), normal human serum (lane 7). (B) Immunoblot of SDS-PAGE separated specific granules incubated with a human anti-Lf positive ReA serum (lane 1), whole granulocyte extract incubated with anti-BPI positive reactive arthritis $(\operatorname{Re} A)$ serum (lane 2$)$, and an $\operatorname{Re} A$ serum reacting with an unknown antigen of approximately $16 \mathrm{kDa}$ (lane 3). Lanes 4-6 illustrate separated azurophil granules incubated with mouse monoclonal anti-Cat $G$ (lane 4), anti-HLE (lane 5), and a human ReA serum, negative in all six ANCA-ELISAs, staining a smear in the 28-34 $k D a$ region (lane 6$)$.

G-ANCA was found in only one patient with $\mathrm{ReA}$, whereas seven UC sera were positive $(\mathrm{p}<0.005)$.

\section{Discussion}

In this study we found that ANCA were common among patients with ReA. Thirty two per cent had antibodies against at least one of the six antigens tested for in ELISA. Antibodies against Lf were shown to be most prevalent followed by BPI-ANCA in both ELISA and immunoblotting experiments. There was a certain correlation between ELISA and IB results for BPI-ANCA and Lf-ANCA in that almost all ELISA positive sera also showed reactivity with the same antigens in IB. However, significantly more sera stained positive in IB, possibly owing to greater sensitivity of this assay.

To assign the reactivities obtained in IB to antigens of neutrophil subcellular fractions, IB was performed with extracts of whole neutrophils, azurophilic and specific granules. The 
major reactivity to a band of $78 \mathrm{kDa}$ corresponding to $\mathrm{Lf}$ was seen equally on granulocyte and specific granule extracts, whereas the reactivity to the $55 \mathrm{kDa}$ antigen corresponding to BPI was seen exclusively on whole granulocyte extracts. We failed to show reactivity to this antigen on the azurophilic granule blots. Reaction to unknown antigens of $60 \mathrm{kDa}$ and 16 $\mathrm{kDa}$ were noted in a few serum samples in both specific granule and whole cell extracts. A few ReA sera reacted weakly on blots of azurophilic granules in the 27-32 kDa region, though none reacted in ELISA with antigens of the corresponding molecular weight range-that is, PR3, HLE, or Cat G.

In all disease groups $30-50 \%$ of sera recognised more than one antigen in ELISA. This is in contrast with ANCA found in primary vasculitic disorders, where only a few distinct antigens seem to be recognised. ${ }^{17}$ The levels of antibody against MPO and PR3 were mostly low or borderline. This applied especially to the group of RA sera, where an unexpectedly high number of patients turned out to be positive in the MPO-ANCA ELISA (47\%). The $17 \%$ PR3-ANCA positive sera in the RA/UC control group is not significantly different from the $14 \%$ PR3-ANCA positive found among disease controls (who were suspected to be ANCA negative) in the European Commission (EC/BCR) project for ANCA assay standardisation ${ }^{18}$ of idiopathic systemic vasculitis. ${ }^{18}$

A similar pattern was found in recent studies, in which Brimnes et al tested RA and UC sera in ELISA for antibodies against different neutrophil autoantigens. ${ }^{19}{ }^{20} \mathrm{~A}$ considerable proportion of serum samples reacted in more than one of the ELISAs - for example, $29 \%$ of RA sera were found positive in MPO-ANCA and $32 \%$ of sera were PR3ANCA positive; however, most were only weakly positive.

In ReA, unlike most other ANCA associated conditions, the disease can take an acute self limiting course or develop into a chronic or chronic intermittent disease state with a potentially severe debilitating outcome. Clearly, more ANCA positive sera were found in the group of patients with chronic $v$ acute ReA disease, indicating that the generation of these autoantibodies requires a certain period of time to develop. Whether the presence of ANCA plays a part in the pathogenesis of chronic disease or is merely a consequence thereof is not possible to elucidate from this study.

When the results from the group with chronic ReA were compared with UC/RA disease control sera, there seemed to be greater similarities between ReA/UC than between ReA/RA or UC/RA for Lf-ANCA and BPIANCA, both being more prevalent in UC and chronic ReA. Cat G-ANCA, however, were found in significantly more UC than ReA serum samples. P-ANCA is a common finding in IBD, mainly in UC and to a lesser extent in Crohn's disease. ${ }^{21-23}$ Some investigators have reported a high prevalence of Lf-ANCA and BPI-ANCA in UC. ${ }^{711124}$ There is a strong link between IBD and the seronegative spondyloarthropathies, and gut inflammation (mainly subclinical) resembling IBD has been reported in about $70 \%$ of patients with chronic ReA or ankylosing spondylitis. ${ }^{25}$ Taking this into account, it is not surprising that ANCA is a common finding not only in UC but also in spondyloarthropathies, as shown in the present study.

There was a discrepancy between results obtained by IIF microscopy and ELISA in that only about $50 \%$ of sera with a P-ANCA pattern reacted to any of the six antigens used in ELISA. This applied to sera from all disease groups and may depend upon several factors such as the avidity of the autoantibodies, epitope exposure, conformational changes/ denaturation of the antigens, etc. When the eight P-ANCA positive sera from the patients with $\operatorname{ReA}$ were analysed by immunoblotting, two samples failed to react with any of the antigen preparations used. This may be due to similar factors.

The practical implications of developing antibodies against neutrophil granule constituents are difficult to determine. Both Lf and BPI are parts of the innate immune system and are released from neutrophils during activation. It has long been known that $\mathrm{Lf}$ can act bacteriostatically by binding iron, but more importantly it exerts direct bactericidal activity. ${ }^{26}$ Lf can also stimulate phagocytic activity of neutrophils. ${ }^{27}$ However, Lf, BPI, and azurocidin (heparin binding protein) can neutralise lipopolysaccharide, thereby preventing Gram negative bacteria from activating neutrophils. ${ }^{28}$ By binding catalytic iron, which may be generated through cell destruction in the inflammatory process, Lf may prevent hydroxyl radical mediated tissue injury associated with neutrophil oxidant production. ${ }^{29}{ }^{30}$ Experimentally it has been shown that anti-Lf antibodies can increase both the magnitude and duration of hydroxyl radical formation. ${ }^{31}$ Theoretically, one might expect that the presence of such autoantibodies could impair the immune system, in that Lf/BPI become attenuated in their physiological actions-for example, in protection of the host from invading microorganisms. This may apply especially to ReA, where inadequate handling of foreign bacterial antigens seems to be part of the pathogenesis. ${ }^{32}$

In conclusion, autoantibodies against neutrophil granule constituents occur frequently in ReA. By using different immunological methods it was shown that the dominant reactivity was directed against Lf and BPI. In contrast with primary vasculitic disorders, several sera recognised more than one antigen, possibly indicating that the driving force for ANCA production in $\mathrm{ReA}$ and the UC/RA control groups differs from that in vasculitides.

\footnotetext{
1 Schultz DR, Tozman EC. Antineutrophil cytoplasmic antibodies: major autoantigens, pathophysiology and disease association. Semin Arthritis Rheum 1995;25:143-59. Muller Kobold AC, van der Geld YM, Limburg PC, Tervaert JW, Kallenberg CG. Pathophysiology of ANCAassociated glomerulonephritis. Nephrol Dial Transplant 1999;14:1366-75.
} 
3 Gross WL, Csernok E, Flesch K. Classic anti-neutrophil cytoplasmic autoantibodies (cANCA), "Wegener's autoantigen" and their immunopathogenetic role in 993;3:171-84

4 Skogh T, Dahlgren C, Holmgren K, Peen E, Stendahl O. Anti-granulocyte antibodies (C-ANCA, P-ANCA, GSANA) studied by confocal scanning laser fluorescence microscopy, ELISA and chemiluminescence techniques. Scand J Immunol 1991;34:137-45

5 Coremans IE, Hagen EC, Daha MR, van der Woude FJ, van der Voort EA, Kleijberg-van der Keur C, et al. Anti-lactoferrin antibodies in patients with rheumatoid arthritis are associated with vasculitis. Arthritis Rheum 1992;35:1466-75.

6 Schnabel A, Csernok E, Isenberg D, Mrowka C, Gross WR. Antineutrophil cytoplasmic antibodies in systemic lupus erythematosus. Arthritis Rheum 1995;38:633-7.

7 Peen E, Almer S, Bodemar G, Ryden B-O, Sjölin C, Tejle $\mathrm{K}$, et al. Antilactoferrin antibodies and other types of ANCA in ulcerative colitis, primary sclerosing cholangitis ANCA in ulcerative colitis, primary scler

8 Halbwachs-Mecarelli L, Nusbaum P, Nöel LH, Reumaux D, Erlinger S, Grunfeld JP, et al. Antineutrophil cytoplasulcerative colitis, Crohn's disease and primary sclerosing cholangitis. Clin Exp Immunol 1992;90:79-84

9 Schmitt WH, Csernok E, Flesch BK, Hauschild S, Gross WL. Autoantibodies directed against lysozyme: a new target antigen for antineutrophil cytoplasmic antibodies (ANCA). In: Gross WL, ed. ANCA associated vasculitidis. New York: Plenum Press, 1993:267-72.

10 Stoffel MP, Csernok E, Hertzberg C, Johnston T, Carroll SF, Gross WL. Anti-neutrophil cytoplasmic antibodies
(ANCA) directed against bactericidal/permeability increasing protein (BPI): a new seromarker for inflammatory howel diseese and associated disorders. Clin Exp Immunol 1996;104:54-9.

11 Walmsley RS, Zhao MH, Hamilton MI, Brownlee A, Chapman P, Pounder RE, et al. Antineutrophil cytoplasm autoantibodies against bactericidal/permeability increasing protein in inflammatory bowel disease. Gut 1997;40: protein

12 Locht H, Peen E, Skogh T. Antineutrophil cytoplasmic antibodies in reactive arthritis. J Rheumatol 1995;22 $2304-6$.

13 Heegaard NHH, Jakobsen DR, Klattschou D. Purification of Wegener's granulomatosis autoantigen, proteinase 3 , from neutrophils by Triton X-114 extraction of azurophilic granules. Anal Biochem 1997;253:259-62.

14 Stummann L, Wiik A. A simple high yield procedure for purification of human proteinase 3, the main molecular target of cANCA. J Immunol Methods 1997;206:33-42.

15 Audrain AP, Reumaux D, Gerson F, Duthilleul P, Wiik A Muller J-Y, et al. Letter to the editor. J Immunol Methods 1999;222:219-20.

16 Borregaard N, Heiple JM, Simons ER, Clark RA. Subcellular localization of the b-cytochrome component of the human neutrophil microbicidal oxidase: translocation during activation. J Cell Biol 1983;97:52-61.
17 Hoffman GS, Specks U. Antineutrophil cytoplasmic antibodies. Arthritis Rheum 1998;41:1521-37.

18 Hagen CE, Daha MR, Hermans J, Andrassy K, Csernok E, Gaskin G, et al. Diagnostic value of standardized assays for anti-neutrophil cytoplasmic antibodies in ideopathic systemic vasculitis. Kidney Int 1998;53:743-53.

19 Brimnes J, Halberg P, Jacobsen S, Wiik A, Heegaard NHH. Specificities of anti-neutrophil autoantibodies in patients with rheumatoid arthritis (RA). Clin Exp Immunol 1997;110:250-6.

20 Brimnes J, Nielsen OH, Wiik A, Heegaard NHH. Autoantibodies to molecular targets in neutrophils in patients with ulcerative colitis. Dig Dis Sci 1999;44:415-23.

21 Ellerbroek PM, Oudkerk Pool M, Ridwan BU, Dolman $\mathrm{KM}$, von Blomberg BME, von dem Borne EAGKr, et al. Neutrophil cytoplasmic antibodies (pANCA) in ulcerative colitis. J Clin Pathol 1994;47:257-62.

22 Abad E, Tural C, Mirapeix E, Cuxart A. Relationship between ANCA and clinical activity in inflammatory bowel diseases: variation in prevalence of ANCA and evidence of heterogeneity. J Autoimmun 1997;10:175-80.

23 Broekroelofs J, Mulder AHL, Nelis GF, Westerveld BD, Cohen Tervaert JW, Kallenberg CGM. Anti-neutrophil cytoplasmic antibodies (ANCA) in sera from patients with inflammatory bowel diseases (IBD). Dig Dis Sci 1994;39: $545-9$.

24 Kossa K, Coulthart A, Ives CT, Pusey CD, Hodgson HJF. Antigen specificity of circulating anti-neutrophil cytoplas-
mic antibodies in inflammatory bowel disease. Eur J mic antibodies in inflammatory bowe

25 Mielants H,Veys EM, Cuvelier C, De Vos M, Goemaere S, De Clercq L, et al. The evolution of spondylarthropathies in relation to gut histology. II. Histological aspects. J Rheumatol 1995;22:2273-8.

26 Dionysius DA, Milne JM. Antibacterial peptides of bovine lactoferrin: purification and characterization. J Dairy Sci 1997;80:667-74.

27 Miyachi $H$, Hashimoto S, Nakajima M, Shinoda I, Fukuwatari Y, Hayasawa H. Bovine lactoferrin stimulates the phagocytic activity of human neutrophils: identification of its active domain. Cell Immunol 1998;187:34-7.

28 Marra MN, Wilde CG, Griffith JE, Snable JL, Scott RW. Bactericidal/permeability increasing protein has endotoxinneutralizing activity. J Immunol 1990;144:662-6.

29 Ellison RT III. The effect of lactoferrin on gram negative bacteria. Adv Exp Med Biol 1994;357:71-90.

30 Britigan BE, Jonathan S, Serody S, Cohen MS. The role of actoferrin as an anti-inflammatory molecule. Adv Exp Med Biol 1994;357:143-56.

31 Britigan BE, Hassett DJ, Rosen GM, Hamill DR, Cohen MS. Neutrophil degranulation inhibits potential hydroxylradical formation. Biochem J 1989;264:447-55.

32 Granfors K, Jalkanen S, von Essen R, Lahesmaa-Rantala R, Isomaki $\mathrm{O}$, Pekkola-Heino $\mathrm{K}$, et al. Yersinia antigens in synovial fluid cells from patiens with reactive arthritis. N Engl J Med 1989;320:216-21. 